\title{
BMJ Open Relationship between labour force satisfaction, wages and retention within the UK National Health Service: a systematic review of the literature
}

\author{
Kweku Andrew Ampadu Bimpong (D) , ${ }^{1}$ Ausaf Khan, ${ }^{1}$ Robert Slight, ${ }^{2}$ \\ Clare L Tolley, ${ }^{1,3}$ Sarah P Slight ${ }^{1,3}$
}

To cite: Bimpong KAA, Khan A, Slight R, et al. Relationship between labour force satisfaction, wages and retention within the UK National Health Service: a systematic review of the literature. BMJ Open 2020;10:e034919. doi:10.1136/ bmjopen-2019-034919

- Prepublication history and additional material for this paper are available online. To view these files, please visit the journal online (http://dx.doi. org/10.1136/bmjopen-2019034919).

Received 28 0ctober 2019 Revised 24 February 2020 Accepted 20 May 2020

\section{Check for updates}

(c) Author(s) (or their employer(s)) 2020. Re-use permitted under CC BY-NC. No commercial re-use. See rights and permissions. Published by BMJ.

${ }^{1}$ School of Pharmacy, Newcastle University, Newcastle upon Tyne, England, UK

2Department of Cardiothoracic Surgery, Newcastle upon Tyne Hospitals NHS Foundation Trust, Newcastle upon Tyne, England, UK

${ }^{3}$ Population Health Sciences Institute, Newcastle University, Newcastle upon Tyne, England, UK

Correspondence to Kweku Andrew Ampadu Bimpong;

k.a.a.bimpong2@newcastle.ac. uk and

Dr Sarah P Slight;

sarah.slight@newcastle.ac.uk

\section{ABSTRACT}

Objectives A systematic review was undertaken to understand the nature of the relationship between the UK National Health Service (NHS) labour force and satisfaction, retention and wages.

Design Narrative systematic review.

Data sources The literature was searched using seven databases in January 2020: MEDLINE (1996-present), the Cumulative Index to Nursing and Allied Health Literature (CINAHL via EBSC0) (1984-present), Embase (1996-present), PsycINF0 (1987-present), ProQuest (1996-present), Scopus (all years) and Cochrane library (all years). We used medical subject headings and key words relating to 'retention', 'satisfaction' and 'wages'. Eligibility criteria for selecting studies Primary research studies or reviews that focused on the following relationships within the NHS workforce: wages and job satisfaction, job satisfaction and retention or wages and retention.

Data extraction and synthesis Two independent reviewers screened all titles, abstracts and full texts, with arbitration by a third reviewer.

Results 27803 articles were identified and after removing duplicates $(n=17156)$, articles were removed at the title $(n=10421)$, abstract $(n=150)$ and full-text $(n=45)$ stages. A total of 31 full-text articles were included. They identified three broad themes, low job satisfaction impacting negatively on job retention, poor pay impacting negatively on staff satisfaction and the limitations of increasing pay as a means of improving staff retention. Several factors affected these relationships, including the environment, discrimination, flexibility, autonomy, training and staffing levels.

Conclusions This review highlighted how multiple factors influence NHS labour force retention. Pay was found to influence satisfaction, which in turn affected retention. An increase in wages alone is unlikely to be sufficient to ameliorate the concerns of NHS workers. More research is needed to identify the role of autonomy on retention. A system leadership approach underpinned by data is required to implement bespoke job satisfaction improvement strategies to improve retention and achieve the goals of the NHS Long Term Plan.
Strengths and limitations of this study

- This is the first systematic review to ascertain the relationship between wages, job satisfaction and retention among the National Health Service (NHS) workforce.

- An extensive literature search was undertaken using seven databases and grey literature.

- The majority of included studies focus on the satisfaction and retention of clinicians, as such our findings may not be generalisable to other NHS professionals.

- The quality appraisal tool used was designed to be used as an educational pedagogic tool.

- The findings of the review are relevant to NHS policymakers and managers seeking to improve staff satisfaction and retention.

\section{INTRODUCTION}

The UK National Health Service (NHS) has faced unprecedented demand for its services in recent times. During the first 3 months of 2018, 5.87 million people attended Accident and Emergency in England of which 1.1 million needed to be admitted for treatment. ${ }^{1}$ It is argued that the size of the workforce has not changed proportionally to the change in demand. The NHS suffers from staff shortages and this has resulted in significant staff pressures. $^{2}$ In the third quarter of 2018/19, $11 \%$ of nursing posts were also left unfilled and figures from the NHS Pay Review Body (NHSPRB) show a total workforce shortage of just over 100000 full-time

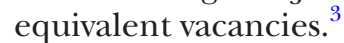

Nationals from the European Union (EU) make up $5.5 \%$ of the NHS workforce and there are 33 trusts where $10 \%$ of the workforce are EU nationals. ${ }^{4}$ Notably, the number of initial nursing registrants from the European Economic Area (EAA) is $\sim 90 \%$ lower than it was at its peak in $2016 \quad(n=9389)$ 


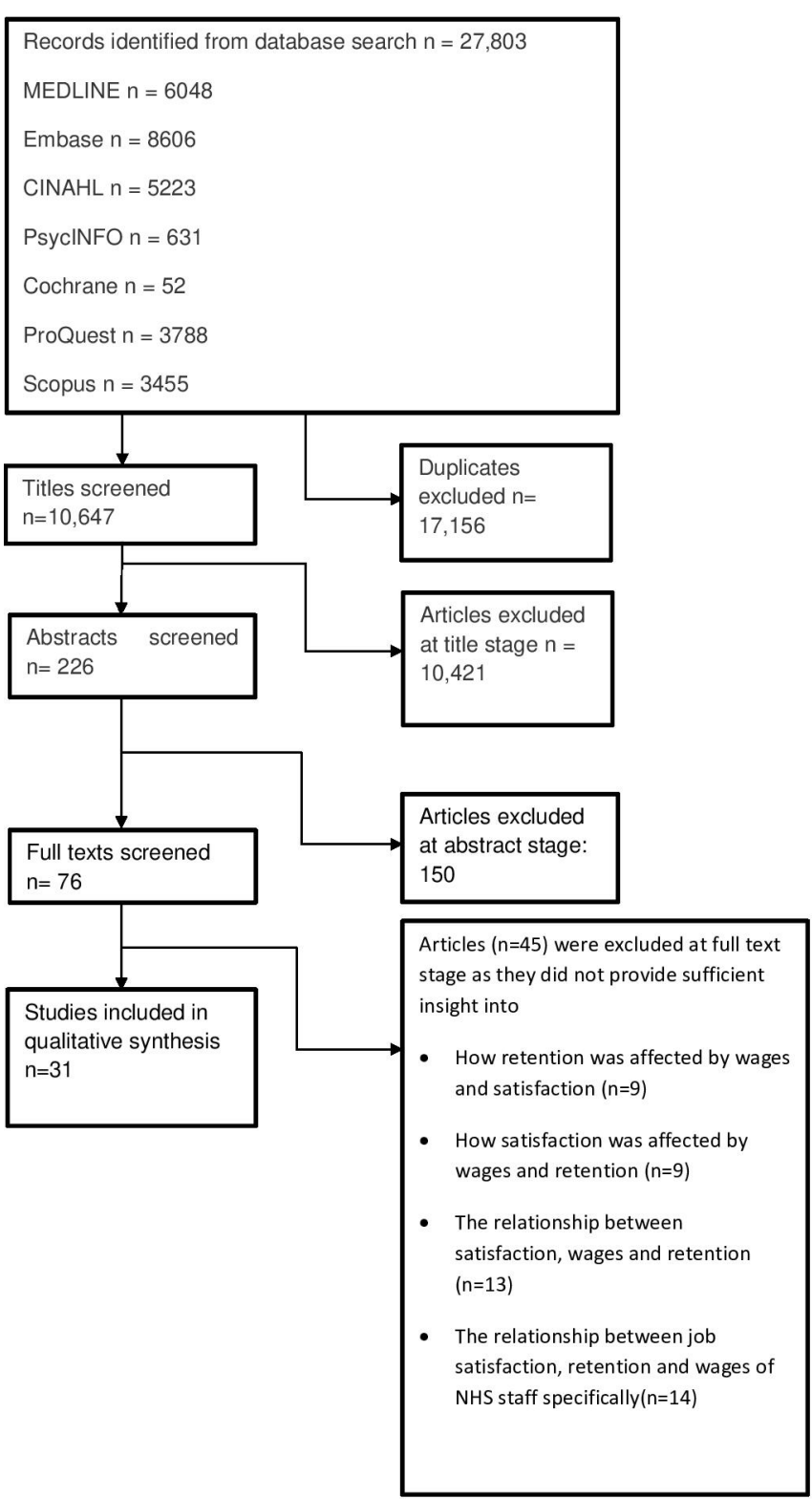

Figure 1 PRISMA diagram detailing the steps taken in the literature search. NHS, National Health Service; PRISMA, Preferred Reporting Items for Systematic Review and MetaAnalysis.

and the percentage of EEA-qualified nurses leaving the register is $16 \%$ greater than it was in 2015 , before the UKs EU membership referendum. ${ }^{3}$ Evidently, the UK's departure from the EU poses workforce concerns.

High staff turnover is related to a number of factors, including poor job satisfaction, which impinges on the quality of care provided to patients. ${ }^{5-7}$ The NHS invests in the development of its workforce and so the loss of trained staff is not merely a monetary loss but a loss of expertise and experience. ${ }^{8}$ Public Health England estimated that sickness absence among NHS staff costed the NHS £2.4 billion in 2015. ${ }^{9}$ NHS England have conceded that more can be done to improve staff health and well-being in view of improving staff retention and acknowledge that 'more of the same' will not enable the delivery of the NHS Long
Term Plan. ${ }^{9}{ }^{10}$ Further to that, the Interim NHS People Plan states that improving retention is the "most immediate action' to be taken to improve staff levels underpinning the importance of this study. ${ }^{10}$

In 2010, a pay cap was imposed on all NHS staff, they thus performed the same or additional work for less remuneration. ${ }^{11} 12$ There is a lack of evidence on how salary may influence NHS staff employment decisions.

We conducted a systematic review to understand the nature of the relationship between NHS employee satisfaction, retention and wages, and to explore the effectiveness of potential satisfaction and retention improvement strategies in the NHS.

\section{METHODS}

This review was reported and conducted in accordance with the Preferred Reporting Items for Systematic Review and Meta-Analysis Protocols. ${ }^{13}$ We defined 'retention' as the ability to retain staff in NHS employment, 'wages' as the regular payment of staff for services provided, and 'satisfaction' as the contentment or fulfilment that one gains from an action-the 'action' being the job carried out by an NHS employee.

\section{Inclusion and exclusion criteria}

Articles were eligible for inclusion if they were primary research studies or reviews that focused on the relationship between either: (a) wages and satisfaction among NHS employees, (b) satisfaction of NHS employees and retention or (c) wages of NHS employees and retention. We excluded any articles that focused on non-NHS employees, factors that affected non-early retirement, recruitment and students, and factors that were not related to satisfaction, wages or retention. Any nonEnglish language publications were also excluded.

\section{Search strategy and rationale}

The search was performed across seven electronic databases in January 2020: MEDLINE (OVID) (1996present), the Cumulative Index to Nursing and Allied Health Literature (CINAHL via EBSCO) (1984-present), Embase (OVID) (1996-present), PsycINFO (OVID) (1987-present), ProQuest (1996-present), Scopus (all years) and Cochrane library (all years). The Open Grey database was also searched to identify sources from UK government boards and agencies, for example, NHSPRB. We used medical subject headings and key words relating to 'retention', 'satisfaction' and 'pay'. The search strategy can be found in online supplementary appendix 1 . The data extraction form can be found in online supplementary appendix 2 .

\section{Study selection}

Two independent reviewers (KAAB and AK) screened all titles, abstracts and full texts, with arbitration by a third reviewer (CLT) if necessary. Reasons for exclusion at the 
full-text stage were outlined in figure 1 and online supplementary appendix 3 .

\section{Quality and anti-bias assurance}

One reviewer evaluated the quality of studies using the Critical Appraisal Skills Programme qualitative cascade; responses can be found in online supplementary appendix $4 .^{14}$

\section{Patient and public involvement}

This research was done without patient and public involvement. Patients were not invited to contribute to the writing or editing of this nor were they invited to comment on the study design.

\section{RESULTS}

Our search revealed 27803 articles, and after removing duplicates $(n=17156)$, articles were removed at the title $(n=10421)$, abstract $(n=150)$ and full-text $(n=45)$ stages. A total of 31 full-text articles were included, the majority of which were conducted and published in the UK $(n=28)$. Three additional papers were published in Australia $(n=1)$, Ireland $(n=1)$ and the Netherlands $(n=1)$ but their focus was on NHS employees. A range of different methods were used, including quantitative $(n=8)$, qualitative $(n=18)$, mixed methods $(n=3)$ and reviews $(n=2)$. We identified the following three key themes: how low job satisfaction impacted negatively on job retention, how poor pay appeared to impact negatively on staff satisfaction and the limitations of increasing pay as a means to improve the retention of NHS staff. Each theme and associated subthemes will be discussed inturn.

\section{Low job satisfaction impacted negatively on job retention}

Several studies reported how job satisfaction among NHS healthcare staff was negatively impacted on by low staff morale, inept management, an inability to partake in professional development or to provide patients with the desired level of care. ${ }^{15-18}$

One cross-sectional study measured how satisfied General Practitioners (GPs) were with their job using the Warr-Cook-Wall scale and found that those with low job satisfaction were more likely to leave their profession. ${ }^{19}$ Andrews conducted 11 semi-structured interviews with nurses and reported how one respondent 'was no longer happy or satisfied with the job. There was no continuity, a lot of night shifts and weekends, and [it was] also very stressful' ${ }^{20}$ Newman et al conducted interviews with 130 NHS nurses and identified several reasons for dissatisfaction, including staff shortages and a lack of appreciation. Another study conducted in-depth interviews with 58 nurses and found that low morale appeared to influence their decision to leave the NHS. ${ }^{15} 21$

However, many NHS employees appeared to join the profession for its career opportunities, and several studies showed how they were less inclined to leave unsatisfactory roles if they felt that there were opportunities to enhance their career prospects. ${ }^{1521-23}$ Job satisfaction also appeared to vary between professions, locations, organisational settings, gender and race, with white employees more likely to have higher job satisfaction than black and ethnic (BME) staff and women having greater job satisfaction than men. ${ }^{24-28}$ Adams and Bond found that larger workforces with more devolved organisational structures appeared to create more of a positive experience for some nurses as they had better teamwork and more innovation, all possibly contributing to increased retention. ${ }^{29}$

\section{Poor pay appeared to impact negatively on staff satisfaction}

A number of studies highlighted how poor pay influenced staff job satisfaction. ${ }^{15} 30$ Storey et al found that poor pay was a major source of dissatisfaction among older primary care nurses, with another study reporting how nurses did not feel adequately compensated for the work they performed. ${ }^{24}{ }^{31}$ Hutton et al conducted a survey and found that $72.2 \% \quad(n=658)$ of radiographers were dissatisfied with their pay rise prospects. ${ }^{32}$ Furthermore, only $36 \%(n=236)$ of all respondents were satisfied with their pay prospects. ${ }^{32}$ One study analysed 16707 nurse responses to the Care Quality Commission's annual NHS national staff survey and found that they were more likely to continue in the profession if they were satisfied with their pay. ${ }^{33}$

\section{The limitations of increasing pay as a means to improving staff retention}

Several studies acknowledged that increasing pay alone was not sufficient to maintain staff retention. ${ }^{3435}$ Frijters $e t$ al found that the higher the predicted private sector wage relative to the NHS wage, the more likely nurses were to leave the NHS. ${ }^{35}$ Agency nurses often receive higher rates of pay than those contracted to work for the NHS, which may influence employees intentions to leave. ${ }^{8}$ Frijters $e t$ al suggested that by increasing the hourly wage by $10 \%$, the percentage of nurses leaving the NHS each year would decrease by $0.66 \%$ and 2119 nurses would be retained; however, only $2 \%$ of the cost of increasing wages would be saved by lower turnover costs in a year. ${ }^{35}$ Storey et al conducted a cross-sectional survey with female primary care and community nurses and found that their pension, more pay and reduced working hours near retirement encouraged nurses across all age groups to remain in the NHS. ${ }^{36}$ The study also found that a significantly larger proportion of younger nurses felt that pay was important. ${ }^{36}$ Robinson et al found that newly qualified nurses were most dissatisfied with their pay and that it was the main reason for why they considered leaving their job. ${ }^{34}$ Simoens et al found that GPs who had a household income equal to or less than $£ 70000$ in 2002 were more likely to report higher intentions to quit than those with a higher household income. Although wages and household income have likely changed over the years, these sentiments have been echoed in more recent studies. ${ }^{18} 19$ Lambert et al sent questionnaires in 2011 and 2015 to doctors (aggregated response $n=5291$ ), 3 years after they 
graduated, to identify reasons for considering leaving medicine or the UK. Almost two thirds n=3145 (60.3\%) of respondents were not definitely intent on staying in UK medicine and one of the top reasons identified was 'UK pay and conditions'. ${ }^{18}$ Interestingly, those surveyed in 2015 cited reasons relating to 'UK pay and conditions' much more frequently compared with those surveyed in 2011 (21.6\% vs $7.7 \%$, respectively). ${ }^{18}$

However, some studies suggested that pay was not the only factor that influenced retention. Purvis and Cropley interviewed nurses $(n=223)$ and concluded that the decision for nurses to leave the NHS was not solely related to poor pay and conditions but also what they wanted from their 'exchange relationship,' for example feeling valued and gaining recognition as well as work partnerships. ${ }^{37}$ Drennan et al, reported how one nurse felt that: "pay is important, but most people don't come into nursing expecting high salaries-they have other motivations'. Frijters et al found that for a large number of nurses, high wages did not compensate for poor working conditions, for example discrimination and high workload. ${ }^{35}$ Investment in 'robust systems of communication', security and conflict resolution may also improve how nurses feel about their work and therefore influence retention, alongside pay. ${ }^{16}$ For example, Newman et al ascribed the loss of traditional rewards (ie, praise and social approval) as a contributing factor for poor retention in nurses. ${ }^{15} 37$ Loan-Clarke et alsurveyed 719 Allied Health Professionals (AHPs) and revealed how pensions were more important than pay for AHPs who worked for the NHS in contrast to AHPs who did not work for the NHS. ${ }^{38}$

\section{DISCUSSION}

This review recognises that job satisfaction is affected by morale, the quality of care provided by staff and professional development opportunities, all of which is arguably influenced by management and ultimately policy within the NHS. ${ }^{15-17}$ This review also established the negative effect that poor pay has on job satisfaction, yet an increase in pay alone was not, however, seen to improve staff retention. ${ }^{15} 30343539$ We found a clear relationship between job satisfaction and retention, and by increasing pay you can potentially increase satisfaction and therefore retention in the NHS. ${ }^{16} 364041$ This review discusses the above findings in turn with future recommendations (table 1).

Our review found a clear relationship between NHS employees' job satisfaction and the quality of care that they felt they provided. ${ }^{5} 153242$ Poor staffing levels and increased workloads can contribute to reduced job satisfaction. ${ }^{1724293643}$ NHS employers have used a range of strategies to try and deal with staff shortages, including using agency staff (locums) on a short-term basis; however, this is not a sustainable solution. ${ }^{8} 1544$ Despite caps on the amount of money a healthcare provider can pay agency workers, hospitals have been known to breach these rules in order to meet the minimum staffing levels required to provide a safe environment. ${ }^{44}$ Furthermore, this approach may adversely affect the quality of care received by patients, due to problems surrounding the quick integration of locums into teams. ${ }^{45}{ }^{46}$ NHS nurses and AHPs are tempted by the better pay and flexibility agency work can offer. ${ }^{38} 44$ Employees who are less concerned with pensionable benefits are therefore more likely to leave the NHS, particularly when job satisfaction is low. ${ }^{8}$ Preliminary plans outlined in the Interim NHS People Plan to create collaborative staff banks have the potential to increase flexibility and the impact of this should be closely followed.

Retention may also be affected by the manner in which the NHS treats its staff, suggesting that valuing employees could improve the dynamic within the NHS workplace environment. ${ }^{1523}$ Effective leadership can ensure that

Table 1 A summary of potential recommendations elicited and developed from findings in selected articles

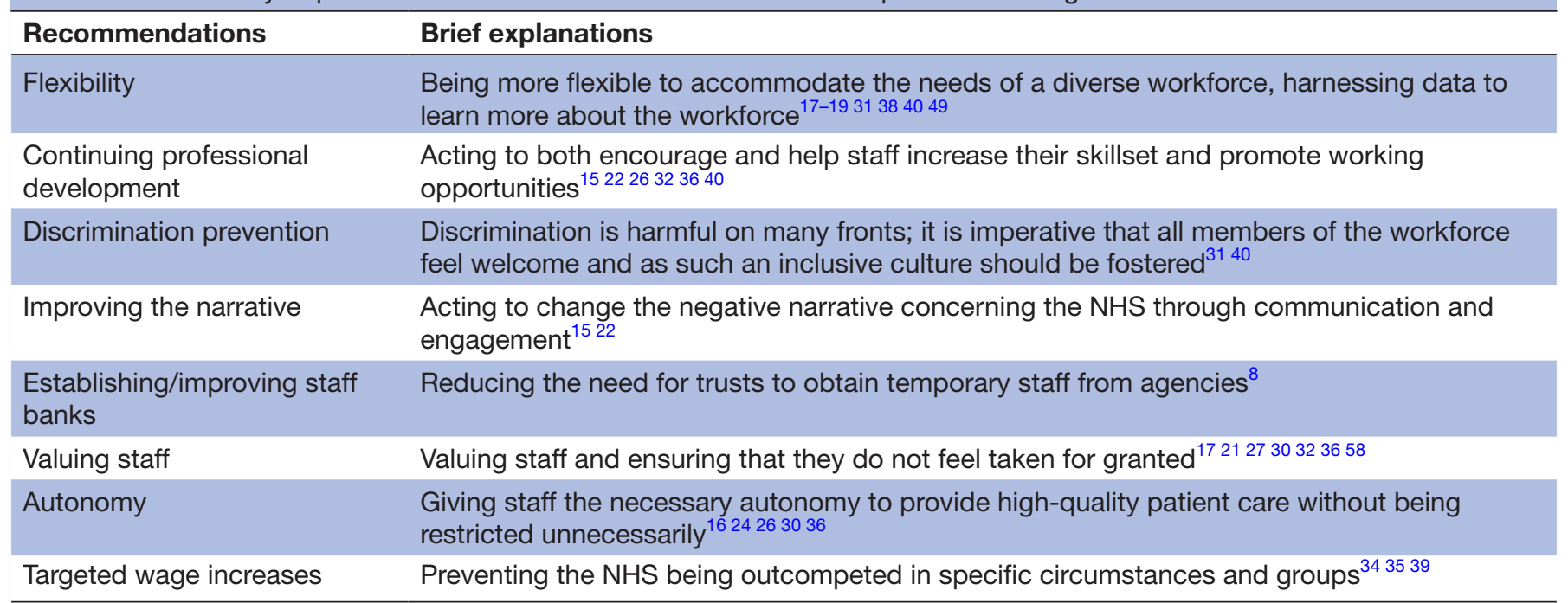

NHS, National Health Service. 
staff feel valued and supported. ${ }^{15}$ Never has this been so pertinent as in modern times, with factors such as Brexit dominating the UK's political landscape. ${ }^{47}$ Freeing up departments to prepare for Brexit resulted in a fast-tracked 1-year spending round, as opposed to the anticipated 3-4year budgets consequently hindering the deliverability of workforce and capital elements included in the long-term plan. ${ }^{47}$ Flexible working arrangements should be offered and could allow nurses that may ordinarily retire, to opt-out of exhaustive tasks as well as providing flexible working patterns. ${ }^{48}$ Efforts such as these may result in NHS staff feeling better valued, as they would still be able to undertake a large part of their role while also imparting their experience on younger peers. ${ }^{23} 364950$ Flexible working hours may also cater to those with young families. ${ }^{51}$ While the pay may have a significant influence on satisfaction among younger nurses, it is unlikely to compensate for discrimination and feelings of being undervalued..$^{31} \mathrm{~A}$ 'one size fits all' approach to improve retention and job satisfaction is clearly unlikely to be successful-a more targeted approach reinforced by the use of data is, therefore, to be recommended.

The Interim People Plan points towards actions to embed the Workforce Race and Disability Equality Standard, and to close the gender pay gap. ${ }^{52}$ Recent research has also identified an ethnic pay gap among NHS doctors, which may result in staff feeling less valued. ${ }^{53}$ The 2019 Workforce Race Equality Standard report stated that $15.3 \%$ of BME staff personally experienced discrimination at work from other colleagues compared with $6.4 \%$ of their white colleagues; the former percentage has risen over the last 4 years. ${ }^{52}$ An evidence-based approach is required to develop and implement interventions to improve equality-related matters and effective system leadership will be vital to enable a cultural change.

This review highlighted the importance of professional development in retaining a satisfied productive workforce. ${ }^{15} 36$ Many healthcare workers felt that their future prospects had a fundamental role to play in both their happiness and job satisfaction. ${ }^{15} 182122364054 \mathrm{~A}$ lot of staff join the NHS as a means of obtaining and developing skills; staff should have access to continuing professional development (CPD) schemes alongside financial support and encouragement to obtain additional qualifications, if desired. ${ }^{40}$ Indeed, a lack of CPD access has been highlighted as an inhibitor of retention; however, research suggests that CPD is not a panacea, particularly for certain employer groups, for example, older staff. ${ }^{365}$ For example, apathy towards CPD resources among older staff may stem from the usage of resources that are not adapted towards their needs. ${ }^{314}$ Care is therefore needed to avoid alienating certain groups of the workforce, for example, shift workers and older staff. ${ }^{31}$ Employers may find investment in CPD more beneficial in terms of job satisfaction and retention than a corresponding increase in wages. ${ }^{24}$ Moriarty et al however acknowledge that there are difficulties surrounding the ability to directly demonstrate benefits for patients and improved retention. Local variation is known to result in differences in the standard of CPD opportunities offered. ${ }^{26}{ }^{55}$ This highlights the need for a whole system approach to identify how CPD could be utilised to improve satisfaction and thus retention among different employer groups. ${ }^{55}$

Gray et al suggest using both CPD and increased autonomy to improve employee satisfaction, particularly in light of the specialisation of the workforce. ${ }^{1026}$ Autonomy is thought to have a strong influence on job satisfaction, yet different roles and environments afford staff varying levels of independence, and standardisation efforts may reduce autonomy. ${ }^{2631}$ The Interim NHS People Plan touches on many of the recommendations in this review; however, further research is needed to understand how autonomy can be retained, while supporting efforts to standardise and improve the quality of care.

National Institute for Health and Care Excellence and several other health-orientated bodies have observed that acting to improve the well-being of employees can have a profoundly positive impact for staff and patients alike. ${ }^{356}$ The Bewick independent review of the cardiac surgery service at St Georges Hospital, for example, found that staff felt poor surgery outcomes that were inevitable as a result of the negative "pervading atmosphere.57 This may be further compounded by issues such as staff shortages and stress in the workplace, both of which may result in employees being more likely to consider their employment status. ${ }^{33} \mathrm{~A}$ cumulative disorder referred to as 'burnout' can affect an individual on an emotional, cognitive and behavioural level. ${ }^{32} 5658$

The majority of included literature focused on nurses and doctors, and so our findings may not be generalisable to other professionals; it is, however, nursing retention rates that are of most concern. ${ }^{10}$ We also acknowledge that a notable proportion of studies and data discussed concern England, despite the NHS consisting of patients from Scotland, Wales and Northern Ireland. This highlights the need for more research into the NHS workforce outside of England concerning satisfaction and retention. No articles were excluded as a result of poor quality; the quality appraisal tool used was however designed to be used as a pedagogic tool.

\section{CONCLUSION}

This is the first systematic review to ascertain the relationship between wages, job satisfaction and retention among the NHS workforce. We identified a close relationship between satisfaction and retention; poor satisfaction increases the likelihood of staff leaving the NHS. An increase in pay was shown to increase retention by improving satisfaction; however, the extent to which it does so varies among different groups and the cost-benefit of this approach is questionable. The literature suggests that a combination of non-monetary factors affect NHS staff intentions to leave. Creating bespoke CPD regimes, increasing flexibility and providing employees with the means to provide a higher quality of care may offer some potential solutions to improve 
retention. Further work is required to understand the interaction between autonomy and standardisation of care, on retention. A cultural shift is required to improve equality matters and maintain staff well-being; a system leadership approach underpinned by data is therefore warranted.

\section{Twitter Kweku Andrew Ampadu Bimpong @kwekubimpong}

Contributors SPS and RS conceived this review. KAAB and AK conducted the literature search and extracted the data. KAAB led the writing of this manuscript, with all other co-authors (SPS, RS, CLT and AK) commenting on subsequent drafts. All authors gave their approval for the final version to be published.

Funding This project has received funding from the European Union's Horizon 2020 research and innovation program MedEye under grant agreement No. 730731.

Competing interests None declared.

Patient consent for publication Not required.

Provenance and peer review Not commissioned; externally peer reviewed.

Data availability statement All data relevant to the study are included in the article or uploaded as supplementary information.

Open access This is an open access article distributed in accordance with the Creative Commons Attribution Non Commercial (CC BY-NC 4.0) license, which permits others to distribute, remix, adapt, build upon this work non-commercially, and license their derivative works on different terms, provided the original work is properly cited, appropriate credit is given, any changes made indicated, and the use is non-commercial. See: http://creativecommons.org/licenses/by-nc/4.0/.

ORCID iD

Kweku Andrew Ampadu Bimpong http://orcid.org/0000-0002-0773-1856

\section{REFERENCES}

1 NHS Improvement. Performance of the NHS provider sector for the year ended 31 March 2018 [Internet], 2018. Available: https:// improvement.nhs.uk/documents/2852/Quarter_4_2017-18_ performance_report.pdf [Accessed 7 Sep 2019].

2 BMA. Working in a system under pressure [Internet]. Available: https://www.bma.org.uk/collective-voice/influence/key-negotiations/ nhs-pressures/working-in-a-system-under-pressure [Accessed 5 Nov 2018].

3 Hird P. National health service pay review body 32nd report, 2019. Available: https://www.gov.uk/government/organisations/nhs-payreview-body [Accessed 11 Feb 2020].

4 Baker C. NHS staff from overseas: statistics, 2019. Available: https:// researchbriefings.parliament.uk/ResearchBriefing/Summary/CBP7783 [Accessed 11 Feb 2020].

5 Newman K, Maylor U, Chansarkar B. The nurse retention, quality of care and patient satisfaction chain. Int J Health Care Qual Assur Inc Leadersh Health Serv 2001;14:57-68.

6 McNeese-Smith DK. A content analysis of staff nurse descriptions of job satisfaction and dissatisfaction. J Adv Nurs 1999;29:1332-41.

7 Investing in success, NHS Providers. NHS priorities for the new government [Internet], 2017. Available: http://nhsproviders.org/ media/2933/investing-in-success-briefing.pdf [Accessed 10 Nov 2018].

8 Drennan VM, Halter M, Gale J, et al. Retaining nurses in metropolitan areas: insights from senior nurse and human resource managers. $J$ Nurs Manag 2016;24:1041-8.

9 NHS staff health \& wellbeing, NHS England. CQUIN 2017-19 Indicator 1 Implementation Support [Internet], 2018. Available: https://www.england.nhs.uk/wp-content/uploads/2018/05/staffhealth-wellbeing-cquin-2017-19-implementation-support.pdf [Accessed 10 Nov 2018].

10 NHS Improvement. Interim NHS People Plan [Internet], 2019. Available: https://improvement.nhs.uk/resources/interim-nhs-peopleplan/ [Accessed 11 Feb 2020].

11 Roberts A, Marshall L, Charlesworth A. A decade of austerity? The funding pressures facing the NHS from 2010/11 to 2021/22. London: Nuffield Trust [Internet], 2012. Available: https://www.nuffieldtrust. org.uk/research/a-decade-of-austerity-the-funding-pressures-facingthe-nhs-from-2010-11-to-2021-22

12 Francis R. Report of the mid Staffordshire NHS Foundation trust public inquiry: Executive summary The Stationery Office; 2013: 126 p.
13 Shamseer L, Moher D, Clarke M, et al. Preferred reporting items for systematic review and meta-analysis protocols (PRISMA-P) 2015: elaboration and explanation. BMJ 2015;349:g7647.

14 CASP. CASP Checklists [Internet]. CASP - Critical Appraisal Skills Programme. Available: https://casp-uk.net/casp-tools-checklists/ [Accessed 12 Nov 2018].

15 Newman K, Maylor U, Chansarkar B. "The nurse satisfaction, service quality and nurse retention chain": implications for management of recruitment and retention. J Manag Med 2002;16:271-91.

16 Barron D, West E, Reeves R. Tied to the job: affective and relational components of nurse retention. J Health Serv Res Policy 2007;12 Suppl 1:46-51.

17 Hann M, Reeves D, Sibbald B. Relationships between job satisfaction, intentions to leave family practice and actually leaving among family physicians in England. Eur J Public Health 2011;21:499-503.

18 Lambert TW, Smith F, Goldacre MJ. Why doctors consider leaving UK medicine: qualitative analysis of comments from questionnaire surveys three years after graduation. J R Soc Med 2018;111:18-30.

19 Simoens S, Scott A, Sibbald B. Job satisfaction, work-related stress and intentions to quit of Scottish GPs. Scott Med J 2002;47:80-6.

20 Andrews GJ. Nurses who left the British NHS for private complementary medical practice: why did they leave? would they return? J Adv Nurs 2003;41:403-15.

21 Callaghan M. Nursing morale: what is it like and why? J Adv Nurs 2003;42:82-9.

22 Coombs C, Arnold J, Loan-Clarke J, et al. Allied health professionals intention to work for the National health service: a study of stayers, leavers and returners. Health Serv Manage Res 2010;23:47-53. May.

23 Foster S. Making retention strategies work. Br J Nurs 2017;26:251.

24 Joshua-Amadi M. A study in motivation: recruitment and retention in the NHS. Nursing Management - UK 2003;9:14-19.

25 Drennan V, Andrews S, Sidhu R, et al. Attracting and retaining nurses in primary care. Br J Community Nurs 2006;11:242-6.

26 Gray K, Wilde R, Shutes K. Enhancing nurse satisfaction: an exploration of specialty nurse shortage in a region of NHS England. Nurs Manage 2018;25:26-33.

27 Harris RV, Ashcroft A, Burnside G, et al. Facets of job satisfaction of dental practitioners working in different organisational settings in England. Br Dent J 2008;204:E1.

28 Sibbald B, Bojke C, Gravelle H. National survey of job satisfaction and retirement intentions among general practitioners in England. BMJ 2003;326:22.

29 Adams A, Bond S. Staffing in acute hospital wards: Part 1. The relationship between number of nurses and ward organizational environment. J Nurs Manag 2003;11:287-92.

30 Sibbald B, Enzer I, Cooper C, et al. Gp job satisfaction in 1987, 1990 and 1998: lessons for the future? Fam Pract 2000;17:364-71.

31 Storey C, Cheater F, Ford J, et al. Retention of nurses in the primary and community care workforce after the age of 50 years: database analysis and literature review. J Adv Nurs 2009;65:1596-605.

32 Hutton D, Beardmore C, Patel I, et al. Audit of the job satisfaction levels of the UK radiography and physics workforce in UK radiotherapy centres 2012. Br J Radiol 2014;87:20130742.

33 Carter MR, Tourangeau AE. Staying in nursing: what factors determine whether nurses intend to remain employed? J Adv Nurs 2012;68:1589-600.

34 Robinson S, Murrells T, Smith EM. Retaining the mental health nursing workforce: early indicators of retention and attrition. Int $J$ Ment Health Nurs 2005;14:230-42.

35 Frijters P, Shields MA, Price SW. Investigating the quitting decision of nurses: panel data evidence from the British National health service. Health Econ 2007;16:57-73.

36 Storey C, Cheater F, Ford J, et al. Retaining older nurses in primary care and the community. J Adv Nurs 2009;65:1400-11.

37 Purvis LJ, Cropley M. The psychological contracts of national health service nurses. J Nurs Manag 2003;11:107-20.

38 Loan-Clarke J, Arnold J, Coombs C, et al. Retention, turnover and return - a longitudinal study of allied health professionals in Britain Human Resource Management Journal 2010;20:391-406.

39 Ikenwilo D, Scott $A$. The effects of pay and job satisfaction on the labour supply of hospital consultants. Health Econ 2007;16:1303-18.

40 Shields MA, Ward M. Improving nurse retention in the National health service in England: the impact of job satisfaction on intentions to quit. J Health Econ 2001;20:677-701.

41 Larrabee $\mathrm{JH}$, Janney MA, Ostrow CL, et al. Predicting registered nurse job satisfaction and intent to leave. J Nurs Adm 2003;33:271-83.

42 Grol R, Mokkink H, Smits A, et al. Work satisfaction of general practitioners and the quality of patient care. Fam Pract 1985;2:128-35 
43 Tovey EJ, Adams AE. The changing nature of nurses' job satisfaction: an exploration of sources of satisfaction in the 1990s. J Adv Nurs 1999;30:150-8.

44 The King's Fund. What has the impact been of recent caps on NHS agency staff spend? [Internet], 2016. Available: https://www. kingsfund.org.uk/blog/2016/03/nhs-agency-staff-spend [Accessed Feb 2018].

45 NHS Improvement. Performance of the NHS provider sector for the month ended 30 June 18 FINAL [Internet], 2018. Available: https:// improvement.nhs.uk/documents/3209/Performance_of_the_NHS_ provider_sector_for_the_month_ended_30_June_18_FINAL.pdf [Accessed 10 Nov 2018].

46 Murray R. The trouble with locums. BMJ 2017;356:j525.

47 Davies G. Review of capital expenditure in the NHS - National Audit Office (NAO) Report [Internet]. NAO, 2020. Available: https:// www.nao.org.uk/report/review-of-capital-expenditure-in-the-nhs/ [Accessed 11 Feb 2020].

48 Andrews J, Manthorpe J, Watson R. Employment transitions for older nurses: a qualitative study. J Adv Nurs 2005;51:298-306.

49 Gould D, Fontenla M. Strategies to recruit and retain the nursing workforce in England: a telephone interview study. Journal of Research in Nursing 2006;11:3-17.

50 Cope J. NHS pay review body thirtieth report 2017. Department of health and social care; 2017: $179 \mathrm{p}$.

51 Pearson R, Reilly P, Robinson D. Recruiting and developing an effective workforce in the British NHS. J Health Serv Res Policy 2004;9 Suppl 1:17-23.
52 The WRES Implementation team. NHS Workforce Race Equality Standard [Internet]; 2020. https://www.england.nhs.uk/wp-content/ uploads/2020/01/wres-2019-data-report.pdf

53 Appleby J. Ethnic pay gap among NHS doctors. BMJ 2018;362:k3586.

54 Ferguson J, Ashcroft D, Hassell K. Factors influencing job satisfaction in community and hospital pharmacy. Journal of Pharmacy Practice 2013.

55 Moriarty J, Steils N, Manthorpe J, et al. Rapid review on the effectiveness of continuing professional development in the health sector, 2019. Available: https://kclpure.kcl.ac.uk/portal/ en/publications/rapid-review-on-the-effectiveness-of-continuingprofessional-development-in-the-health-sector(deb289ec-8bd247ab-96b5-e5f76b2cb07d).html [Accessed 11 Feb 2020].

56 Imo UO. Burnout and psychiatric morbidity among doctors in the UK: a systematic literature review of prevalence and associated factors. BJPsych Bull 2017;41:197-204.

57 Bewick M. Independent review of cardiac surgery service ST Georges Hospital NHS trust, 2018. Available: https://www.stgeorges. nhs.uk/wp-content/uploads/2018/08/Independent-review-ofcardiac-surgery-\%E2\%80\%93-St-George\%E2\%80\%99s-UniversityHospitals.pdf

58 Appleton K, House A, Dowell A. A survey of job satisfaction, sources of stress and psychological symptoms among general practitioners in Leeds. Br J Gen Pract 1998;48:1059-63. 